hormone therapy or chemotherapy should be prescribed. Many clinicians, particularly those in North America, recommend prophylactic chemotherapy routinely for all patients with any spread to the axillary nodes-and they may be deemed negligent not to do so. Doubts are now being expressed about this policy, however, and the more conservative approach adopted in Britain is gaining ground.

The problem that clinicians have to face is that adjuvant chemotherapy has not been proved to "cure" patients with micrometastases. In some patients it may be important to prolong the disease free interval, but in others systemic treatment may better be reserved for the time when the metastases cause symptoms. Prognostic indicators are only a guide. Some patients with a poor index live out a normal life span and never develop clinically apparent secondary disease. Meanwhile the hope for the future is that with better drugsand perhaps better ways of using the available drugs-adjuvant chemotherapy may improve the results in breast cancer in the same way as the improvement in the outcome of treatment of lymphomas and teratomas.

Clinical research must continue-both to assess new agents and to optimise the use of those currently available. Further research on the biological characteristics of breast cancer with its metastasing potential should help our understanding of the disease, and if markers and simple detectors of hormone sensitivity can be found there should be great strides in the development of potentially curative treatment.

At present the use of cytotoxic drugs as adjuvant therapy should be in the hands of clinicians in specialist units, and when possible patients should be included in studies and clinical trials. Non-toxic adjuvant treatment with tamoxifen will undoubtedly be used widely, but research is still needed on the place of this agent used in this way. There is no reliable information on how much is required or for how long it should be given. These questions should be answered by further clinical trials, and the studies on immunotherapy need repeating and developing.

It can only be an advantage to have as much information as possible on a patient with primary breast cancer. The data collected will given an indication of the pattern and extent of the disease and of the course it is likely to take and will be of help in planning a treatment programme, but the place of adjuvant therapy must still be the subject of research. Many questions remain unanswered. Which patients? What type of treatment? For how long?

DiANA BRINKLEY

Consultant Radiotherapist,

King's College Hospital,

London SE5 9RS

${ }^{1}$ Brinkley D, Haybittle JL. The concept of cure in breast cancer. Leeds: Yorkshire Breast Cancer Group, 1980. (Private publication.)

2 Langlands AO, Pocock SJ, Kerr GR, Gore SM. Long term survival of patients with breast cancer. Br Med $\mathcal{F} 1979$;ii:1247-51.

3 Rubens RD, Hayward JL, Knight RK, et al. Controlled trial of adjuvant chemotherapy with melphalan for breast cancer. Lancet $1983 ; \mathrm{i}: 839-43$.

4 Rossi A, Bonnadonna G, Valagussa P, Veronisi U. Multimodal treatmen in operable breast cancer: five year results of the CMF programme. $\mathrm{Br}$ Med F 1981 ;282:1427-31.

5 Nolvadex Adjuvant Trial Organisation. Controlled trial of tamoxifen as adjuvant agent in management of early breast cancer. Lancet 1983; 257-61.

- Lacour J, Lacour F, Spira A, et al. Adjuvant treatment with polyadenylicpolyuridylic acid in operable breast cancer: updated results of a randomised trial. $\mathrm{Br}$ Med $\mathcal{F} 1984$;288:589-92.

7 Fisher B, Baker M, Wickerham DL, et al. Relation of number of positive axillary nodes to the prognosis of patients with primary breast cancer. An NSABP update. Cancer 1983;52:1551-7.

${ }^{8}$ Haybittle JL, Blamey RW, Elston CW, et al. A prognostic index in primary breast cancer. $\mathrm{Br} \mathcal{F}$ Cancer 1982;45:361-6.

${ }^{9}$ Redding WH, Coombs RC, Monaghan P, et al. Detection of micrometastases in patients with primary breast cancer. Lancet 1983;ii:1271-3.

\section{Day care for patients with psychiatric disorders}

Last year Vaughn reviewed the "disordered development of day care in psychiatry" and made two criticisms. ${ }^{1}$ Firstly, the planning of psychiatric day hospitals and local authority day centres has been poorly coordinated. They are inequitably distributed around Britain, and they vary greatly in the quality of treatment they provide. Few observers disagree with this. ${ }^{2-4}$ Secondly, though some forms of day care have been available for patients with psychiatric disorders for about 40 years, ${ }^{5-7}$ very little is known about either their efficacy or their efficiency. ${ }^{8}$

The tendency towards reduction in the average length of psychiatric inpatient stay may, it seems, be associated with a corresponding increase in the use of day hospitals ${ }^{9}$; but too little attention has been paid to the problems of the "expanding stage army" of long stay psychiatric day patients. ${ }^{10}$ Indeed, the House of Commons Select Committee on Social Services is now conducting its inquiry into community care with special reference to the adult mentally ill and handicapped.

Outpatient care is apparently more economical of time and personnel and on general grounds is preferred to day care for patients with mild psychiatric disorders who are referred to psychiatrists. ${ }^{11}$ Even for patients with serious or chronic psychiatric disorders, however, several studies have been said to show the general superiority of day hospital care over outpatient and inpatient care. ${ }^{12-24}$ The extent to which day care is associated with improvements in either patients' symptoms or their social state is less clear. Moreover, close inspection of these studies invariably shows up methodological inadequacies. For example, the number of patients tends to be small; often there is selection bias, partial or no randomisation, and little control of important variables such as diagnosis, medication, and treatment between discharge and follow up; day care and inpatient care are often ill defined; outcome measures are not standardised or rated blindly; and too many patients are usually lost during follow up. All these reasons reduce the confidence that can be put on the case favouring day care for patients with severe psychiatric disorders.

One series of American reports dealt with the results of a study of 175 newly admitted men and women inpatients with families who were randomly assigned to three groups: standard inpatient care followed by outpatient care; brief admission to hospital followed by day care and discharge as outpatients; and brief admission to hospital followed only by discharge as outpatients. ${ }^{25-31}$ The design of the study was such that any patient readmitted during the two years after the index admission was again given the initially assigned treatment. Day patients were treated on the inpatient service, the main difference between them and inpatients being that they went home at night and weekends. Two thirds had a diagnosis of schizophrenia. Measurements of the patients' psychopathological features, how they functioned socially, the "family burden," and the costs of treatment were made at entry, after three months and six months, and at six monthly intervals up to two years after admission.

The average initial stay was 60 days for the standard group, and 11 days for both the brief groups. There was no difference in readmission rates, but the average number of days of inpatient care in the two years of the study did vary: 115 days for the standard group, 47 days for the group which received day care, and 27 days for the brief group which was merely discharged to the outpatient department after admission. The 
day care group spent an average of 43 days in day care over the two years, but only about half of those eligible used this facility. In summary, the results showed that there were few differences among the treatment groups on any measures of psychiatric and social disorder, either in patients or in their families. When differences did occur they tended to favour the groups receiving brief care. A crude analysis of the costs showed that brief admission to hospital followed by either day or outpatient care was less expensive than standard admission in respect of both hospital costs and costs to the patients' families.

Looking at the problem from another point of view, Linn and her colleagues investigated 162 schizophrenic men having maintenance antipsychotic drugs who were referred for day treatment at the time of discharge from 10 Veterans Administration hospitals. ${ }^{32}$ The patients were randomly assigned to day treatment plus drugs or outpatient drug management alone. In this study day care staff interviewed patients before randomisation to exclude patients who were thought to be inappropriate for referral to day care. Eighty eight per cent of the day care patients attended for a full day. Ten per cent attended less than three days a month. The most frequently prescribed treatments were social and recreational activities, group therapy, individual counselling, occupational therapy, and work counselling and training. Follow up lasted two years, and six monthly assessments were made of the patients' psychiatric symptoms, social functioning, attitudes, time spent out of hospital in the community, and the costs of care. The results showed that all centres seemed to improve the patients' social functioning. Care at six of the centres was found to delay relapse, to reduce symptoms, and to change some of the patients' attitudes. Centres with good results were characterised by the provision of more occupational therapy and a "sustained non-threatening environment." Those with poor results were characterised by more staff hours worked by psychologists and social workers, group psychotherapy, more family counselling, and a high patient turnover.

Few reports of day care programmes have linked a detailed assessment of each patient's physical, psychological, and social needs with particular therapeutic strategies. Falloon and Talbot described such an exercise (based on extensive interviews and observations and a behavioural treatment approach) in which patients' goals were specified in terms of objectively defined behaviour to be achieved on or before a given time. ${ }^{33}$ Good outcome was associated with high levels of participation by patients in defining their own goals. In addition, goals concerned with social and vocational behaviour were achieved more frequently than those concerning symptoms and intrapersonal matters. A similar type of "goal attainment scaling" was used in a comparative evaluation of 56 randomly selected patients who attended two day hospitals. ${ }^{34}$ One used a token economy system and behavioural and educational methods, concentrating on everyday coping and social skills and occupational therapy. The other was more eclectic and used a therapeutic community approach and group and individual psychotherapy. After intake, patients were followed up by interview at three and six months and by telephone at two years. Though the results cannot be regarded as conclusive, the patients who attended the behavioural-educational programme attained more of their therapeutic aims.

This general theme-that certain professional and treatment practices may be of greater benefit than others in terms of staff-patient relations and possibly therapeutic outcome-was also raised by a study of four local authority day centres. ${ }^{35}$ Patient oriented management attitudes were found to be correlated with a more personal approach to patients' problems and an emotionally warmer quality of personal interaction. The crucial question, however, is how far these attitudes can be shown to improve patients' functioning. More studies are needed of the effects of variations in organisational and therapeutic methods on staff and patients.

Hence we do not have satisfactory answers to the crucial questions about day care for patients with severe psychiatric disorder. Clinicians and research workers should be placing more emphasis on the individual assessment and treatment of patients and on the reliable and valid measurement of therapeutic outcome. The kind of detailed local inquiry that is needed is suggested by a survey of long term users of community psychiatric services in Camberwell. ${ }^{36}$ This provided information on the demographic, social, and clinical characteristics of patients; the practices of day and residential units in relation to the social behaviour of attenders; the part played by relatives; and the needs for, and deployment of, services.

As Wing has said, such exploratory studies cannot provide final answers ${ }^{36}$-but they may suggest where changes in existing services should be made, and this in turn should lead to further evaluative studies in a cycle of planning and evaluation. ${ }^{37}$ More attention also needs to be paid to the part general practitioners have to play in caring for patients with major psychiatric disorders who live in the community. They are especially well placed to mobilise and coordinate family and community resources. Finally, this debate has to recognise the fundamental issue of the future relation between health and social services elements in the care of the mentally ill. In the words of the Department of Health and Social Security: "Most people who need long term care can and should be looked after in the community. This is what most of them want for themselves and what those responsible for their care believe to be best."38 How such a policy is to be implemented is another question. ${ }^{39}$

\section{GREG WILKINSON}

Research Worker,

General Practice Research Unit,

Institute of Psychiatry,

London SE5 8AF

1 Vaughn P. The disordered development of day care in psychiatry. Health Trends 1983;15:91-4.

${ }^{2}$ Edwards C, Carter J. Day services and the mentally ill. In: Wing JK, Olsen $\mathrm{R}$, eds. Community care and the mentally disabled. Oxford: Oxford University Press, 1979.

${ }^{3}$ Royal College of Psychiatrists. Psychiatric rehabilitation in the 1980s. Report of the Working Party on Rehabilitation of the Social and Community Psychiatry Section. London: Royal College of Psychiatrists, 1980.

4 Richmond Fellowship. Mental health and the community. Report of the Richmond Fellowship enquiry. London: Richmond Fellowship Fress, 1983.

${ }^{5}$ Farndale J. The day hospital movement in Great Britain. Oxford: Pergamon Press, 1961.

- Freeman H, Farndale J, eds. Trends in the mental health services. Oxford: Pergamon Press, 1963.

${ }^{7}$ Freeman H, Farndale J, eds. New aspects of the mental health services. Oxford: Pergamon Press, 1967.

${ }^{8}$ Cochrane AL. Effectiveness and efficiency. Random reflections on health services. London: Nuffield Provincial Hospitals Trust, 1972.

Hirsch SR, Platt S, Knights A, Weyman A. Shortening hospital stay for psychiatric care: effect on patients and their families. $\mathrm{Br} \mathrm{Med} \mathcal{F}$ 1979; i:442-6.

10 Pryce IG. An expanding 'stage army' of long stay psychiatric day patients. Br $\mathcal{F}$ Psychiatry 1982;141:595-601.

11 Tyrer PJ, Remington M. Controlled comparison of day-hospital and outpatient treatment for neurotic disorders. Lancet 1979;i:714-6.

12 Meltzof J, Blumenthal RL. The day treatment center: principals, application and evaluation. Springfield, Illinois: Charles C Thomas, 1966.

13 Guy W, Gross M, Hogarty GE, et al. A controlled evaluation of day hospital effectiveness. Arch Gen Psychiatry 1969 ;20:329-38.

14 Weldon E. Day hospital versus outpatient treatment: a controlled study. Psychiatr $Q$ 1979;51:144-50. 
15 Craft M. An evaluation of treatment of depressive illness in a day hospital. Lancet 1958;ii:149-51.

${ }^{16}$ Kris E. Prevention of hospitalisation through relapse control in a day hospital. In: Greenblatt M, ed. Mental patients in transition. Springfield, Illinois: Charles C Thomas, 1961.

17 Zwerling I, Wilder JF. An evaluation of the applicability of the day hospital in the treatment of acutely disturbed patients. Israel Annals of Psychiatry 1966;2:162-85.

18 Wilder JF, Levin G, Zwerling I. A two-year follow-up evaluation of acute psychotic patients treated in a day hospital. Am $\mathcal{F}$ Psychiatry 1966;122:1095-101.

19 Herz MI, Endicott J, Spitzer RL, Mesnikoff A. Day versus inpatient hospitalisation: a controlled study. Am 7 Psychiatry $1971 ; 127: 1371-82$

${ }^{20}$ Ettlinger RA, Beigl A, Feder SL. The partial hospital as a transition from inpatient treatment: a controlled follow-up study. Mt Sinai $\mathcal{F}$ Med $1972 ; 39: 251-7$.

${ }^{21}$ Michaux $\mathrm{MH}$, Chelst MR, Foster SA, et al. Post-release adjustment of day and full-time psychiatric patients. Arch Gen Psychiatry 1973;29: 647-51.

22 Sappington AA, Michaux MH. Prognostic patterns in self-report, relative report, and professional evaluation measures for hospitalised and day care patients. $\mathcal{F}$ Consult Clin Psychol 1975;43:904-10.

23 Washburn S, Vannicelli M, Longabaugh $R$, et al. A controlled comparison of psychiatric day treatment and in-patient hospitalisation. $\mathcal{F}$ Consult Clin Psychol 1976;44:665-75.

${ }^{24}$ Penk WE, Charles HL, Van Hoose TA. Comparative effectiveness of day hospital and inpatient psychiatric treatment. $\mathcal{f}$ Consult Clin Psychol $1978 ; 46: 94-101$.

${ }^{25}$ Herz MI, Endicott J, Spitzer RL, et al. Brief hospitalisation of patients with families: initial results. Am F Psychiatry 1975;132:413-8.

${ }^{26}$ Herz MI, Endicott J, Spitzer RL, et al. Brief versus standard hospitalisation: the families. Am $\mathcal{F}$ Psychiatry 1976;133:795-801.
27 Herz MI, Endicott J, Spitzer RL, et al. Brief hospitalisation: a two year follow up. Am F Psychiatry 1977;134:502-7.

${ }^{28}$ Reibel S, Herz MI. Limitations of brief hospital treatment. Am $\mathcal{f}$ Psychiatry 1976;133:518-21.

${ }^{29}$ Endicott J, Herz MI, Gibbon M. Brief versus standard hospitalisation: the differential costs. Am $\mathcal{F}$ Psychiatry 1978;135:707-12.

${ }^{30}$ Herz MI, Endicott J, Gibbon M. Brief hospitalisation: two year follow up. Arch Gen Psychiatry 1979;36:701-5.

${ }^{31}$ Endicott J, Cohen J, Nee J, Fleiss JL, Herz MI. Brief versus standard hospitalisation: for whom? Arch Gen Psychiatry 1979;36:706-12.

32 Linn MW, Caffey EM, Klett J, Hogarty GE, Lamb HR. Day treatment and psychotropic drugs in the after care of schizophrenic patients. A Veterans Administration cooperative study. Arch Gen Psychiatry 1979; 36:1055-66.

${ }^{33}$ Falloon IRH, Talbot RE. Achieving the goals of day treatment. $\mathcal{F}$ Nerv Ment Dis 1982;170:279-85.

${ }^{34}$ Austin NK, Liberman RP, King LW, De Risi WJ. A comparative evaluation of two day hospitals. Goal attainment scaling of behavior therapy vs milieu therapy. $\mathcal{F}$ Nerv Ment Dis $1976 ; 163: 253-62$.

${ }^{35}$ Shepherd G, Richardson A. Organisation and interaction in psychiatric day centres. Psychol Med 1979;9:573-9.

${ }^{36}$ Wing $\mathrm{JK}$, ed. Long-term community care: experience in a London borough. Psychol Med 1982;12:monograph supplement 2.

${ }^{37}$ Wing JK. Principles of evaluation. In: Wing JK, Hailey AM, eds. Evaluating a community psychiatric service: the Camberwell register. London: Oxford University Press, 1972:11-39.

${ }^{38}$ Department of Health and Social Security. Care in the community. A consultative document on moving resources for care in England. London: DHSS, 1983. (HC(81)9/LAC(81)5.)

${ }^{39}$ Department of Health and Social Security. Health service development care in the community and joint finance. London: DHSS, 1983. (HC(83)6/ LAC(83)5.)

\section{Consensus development conference : coronary artery bypass surgery in Britain}

Since 1978 over 40 consensus development conferences have taken place in the United States under the auspices of the National Institutes of Health. The subjects have been as various as screening for breast cancer, hip joint replacement, and dental sealants. More recently such conferences have been held in Sweden, Holland, and Denmark, and a pilot conference is planned for Britain in November this year. So how does a consensus development conference differ from the growth of a natural consensus or a conventional medical symposium?

A consensus conference deals with a specific technological method, procedure, or programme, discussing its place in medical care. Both the audience and the consensus panel, which produces the statement on the issue, represent a broad range of backgrounds and disciplines. Topics are chosen that are controversial and of public importance. The British conference is being sponsored by the King's Fund in association with the Royal College of Physicians of London and the Royal College of Surgeons of England. Coronary artery bypass surgery is of current concern because of the wide differences in its frequency in different countries (about 125 operations per million population each year in Britain and 650 in the United States).

Each conference seeks to answer a set of questions. For the conference in Britain four issues have been identified. Firstly, what are the pros and cons of coronary artery bypass grafts compared with alternatives for various types of patient in terms of survival and the quality of life? Secondly, what are the indications for various investigations for coronary artery disease? Thirdly, how big are the potential pools of patients for investigations and for coronary artery bypass grafts, taking account of alternative treatments? Are these estimates likely to change substantially in the next 5-10 years? And, finally, what would be the cost and organisational implications of making increased provision for investigation and treatment?

Invited experts will present evidence at a meeting that is open to anyone making prior registration. The panel will listen, ask questions, and at the end prepare its written consensus. This will be presented at the end of the conference with the press invited; it will be published in full shortly afterwards in the $B M \mathcal{F}$. Half the members of the panel will be medical-including a cardiologist, cardiothoracic surgeon, general practitioner, and community physician-and other members will include a statistician, lawyer, philosopher, economist, nurse, and journalist.

If this conference proves a success we hope that a regular consensus programme might be set up as a means of promoting debate of controversial issues both among experts and between doctors and the public.

Anyone wishing to register for the conference should contact Barbara Stocking at the King's Fund, 2 Palace Court, London W2 4HS, telephone 012299361 .

BARBARA STOCKING

Fellow in Health Policy, Innovation, and Evaluation,

King's Fund College,

London W2 $4 \mathrm{HS}$

BRYAN JENNETT

Dean of Medicine,

University of Glasgow,

Glasgow G51 4TF 